\title{
ANÁLISE DO PISTÃO A GASOLINA DO MOTOR AP-1800
}

\author{
AP-1800 ENGINE PISTON ANALYSIS
}

Silmar Coldebella ${ }^{1}$

Salmo Mardegan ${ }^{2}$

\section{RESUMO}

Com o desenvolvimento tecnológico da indústria automobilística nos últimos anos houve um grande número de inovações em diversas áreas, com a elaboração de novas técnicas de fabricação dos produtos, tornando os motores a combustão interna cada vez mais eficientes, resistentes e com maior qualidade e facilidade de fabricação e buscando assim diminuir a poluição gerada pelos mesmos. Este trabalho trata da realização de uma análise do pistão do motor AP 1.8 gasolina. Realizando o analise de diversas características do pistão como potência, torque e entre outras características. E também realizando uma análise computacional da geometria do pistão.

Palavras-Chave: Motor a combustão, análise e pistão.

\section{ABSTRACT}

With the technological development of the automobile industry in recent years there has been a great number of innovations in several areas, with the elaboration of new manufacturing techniques of the products, making internal combustion engines increasingly efficient, resistant and with greater quality and ease of manufacturing and seeking to reduce the pollution generated by them. This work deals with the performance of an AP 1.8 gasoline engine piston analysis. Carrying out the analysis of several characteristics of the piston as power, torque and among other characteristics. And also performing a computational analysis of the piston geometry.

\footnotetext{
${ }^{1}$ Engenheiro Mecânico. Graduado em Engenharia Mecânica pela Universidade Alto Vale do Rio do Peixe (UNIARP). email: (karijomec@hotmail.com)

${ }_{2}^{2}$ Professor Orientador. Graduado em Engenharia, pela Universidade do Estado de Santa Catarina (UDESC), Mestrado em Engenharia de Produção, pela Universidade Federal de Santa Catarina (UFSC) e docente do Curso de Engenharia Mecânica da Universidade Alto Vale do Rio do Peixe.
} 
Keywords: CFD, Combustion, analysis and piston engine.

\section{INTRODUÇÃO}

Com o desenvolvimento tecnológico da indústria automobilística nos últimos anos houve um grande número de inovações em diversas áreas, com a elaboração de novas técnicas de fabricação dos produtos e novas maneiras de projetar os motores, tornando os motores a combustão interna cada vez mais eficientes, resistentes e com maior qualidade e facilidade de fabricação e buscando assim diminuir a poluição gerada pelos mesmos. Os motores a combustão interna de ciclo Otto tiveram o início da sua constituição em 1866, criado por Nikolas August Otto, esse motor tem o princípio de funcionamento que é o ciclo de quatro tempos e o mesmo é utilizado até os dias atuais (KNIES, 2010). Atualmente a indústria está cada vez mais aprimorada melhorando a qualidade e eficiência dos motores, buscando melhoria no projeto e na operação dos motores a combustão interna, em especial no controle de emissões e otimização no consumo de combustível (TILLMANN, 2013).

Este trabalho realiza a análise das características do pistão a gasolina do motor AP-1800. Para isso será realizado um a engenharia reversa da sua forma construtiva criando um modelo 3D do mesmo e em seguida executadas simulações computacionais por analise de elementos finitos para dessa maneira determinar as tensões máximas e mínimas que o mesmo está submetido. E realizando uma análise da potência que este modelo de pistão produz e verificar a taxa de compressão e a cilindra que do mesmo.

Modelos tridimensionais são utilizados em diversas áreas das indústrias, desde de projetos de equipamento a projetos de engenharia civil, facilitando em muitos em diversas etapas de desenvolvimento de projetos. Assim eles têm grande importância nas indústrias de fabricação, onde modelos precisos de peças e montagens são criados usando um software de modelagem 3D de utilizando de sistemas CAD. O processo de desenho é normalmente incremental. Os desenhistas podem especificar pontos, curvas e superfícies e juntá-los para formar o objeto tridimensional. Também podem selecionar modelos de formatos simples, como blocos ou cilindros e especificar suas dimensões, posição e orientação e combina-los 
para construir o seu modelo. O desenho resultante é uma representação digital perfeita, completa e detalhada da geometria do objeto ou da montagem de diversos objetos (ROSSIGNAC, 20??).

Motor é uma máquina para realizar a conversão de qualquer tipo de energia em energia mecânica. Os motores de combustão interna realizam a conversão da energia térmica em energia mecânica através da combustão, a queima de combustível (TILLMANN, 2013). Os motores alternativos, tem o princípio de funcionamento baseado em um sistema de pistão e cilindro, onde o pistão realizado um movimento linear no interior do cilindro e este movimento é transmitido para o virabrequim através da biela, transformando o movimento linear em rotativo. Para exemplificar podemos comparar com o modo que é funciona uma bicicleta, aonde o movimento das pernas o sobe e desce ou o movimento alternativo das pernas é transformado em movimento circular pelos pedais (árvore e manivelas) figura 1. Os motores de movimento alternativo funcionam baseados em dois princípios ou dos motores dois tempos ou quatro tempos (ESALQ, 20??).

Os motores podem ser classificados quanto a ignição que é o processo de que inicia a combustão do combustível, para que isto aconteça a necessidade da presença de oxigênio para dar início à reação. Os motores de combustão interna podem ser baseados em dois tipos de ignição, a faísca também conhecido como ciclo Otto e os motores de ignição espontânea ou Diesel (BRUNETTI, 2013).

Motores de ignição por faísca Ciclo Otto: Nesse tipo de motores de combustão interna, a mistura de arcombustível é admitida, após a admissão a mesma é comprimida até o momento que a faísca da vela que realiza a ignição do combustível, assim na etapa seguinte há expansão do ar e o ciclo finaliza com a exaustão dos gases (VARELLA, 20??).

Motores de ignição espontânea Ciclo Diesel: Nesses tipos de motores o pistão comprimi o ar, até que atinja uma temperatura elevada o suficientemente, assim quando o pistão atinge a altura máxima dele o combustível é injetado no seu interior, assim a ignição ocorre sem haver a necessidade uma vela gerando uma faísca. A temperatura do ar faz com que ocorra a combustão (SILVEIRA, 2013).

E podem ser classificados quanto ao ciclo que é a sequência de processos que se repetem para a geração de trabalho útil. Um tempo é entendido como o curso do pistão. A classificação se divide em dois grupos, motores alternativos a quatro 
tempos e motores alternativos a dois tempos (BRUNETTI, 2013).

Os motores alternativos a quatro tempos os pistões percorre quatro cursos correspondente a duas voltas do virabrequim para que seja completado um ciclo do mesmo. Assim o processo realizado nesses motores é dividido em quatro partes (BRUNETTI, 2013). Um ciclo de trabalho se dá por duas rotações das árvores manivelas, e durante os quatro tempos transmitiu-se trabalho ao pistão somente uma vez (FERRAZ, 2008).

Nos motores alternativos de dois tempos combinam um ciclo que se completa em dois cursos do pistão correspondendo aos quatro ciclos de um motor 4 tempos. Assim a um trabalho gerado a cada volta do virabrequim. Os processos que realiza são os mesmo dos motores 4 tempos, mas aqui alguns deles se sobrepõem (FERRAZ, 2008).

O pistão é o componente que transmite a energia gerada pela expansão dos gases da combustão, ele recebe esta energia e através do pino e da biela ele transmite essa força ao virabrequim. Os pistões normalmente são fabricados em ligas de alumínio ou aço. Na figura 9 é observado um pistão e sua geometria (TILLMANN, 2013). Os pistões atualmente são fabricados de alumínio são os que tem a melhor condução de calor, assim os mantém com uma temperatura mais baixa, sendo esses pistões utilizados em motores de elevada rotação. Os pistões de aço que tem uma pior condução de calor são mais utilizados em motores de baixa rotação. No momento da explosão a temperatura do pistão vai para $350^{\circ} \mathrm{C}$ em sua superfície superior e cerca de $150^{\circ} \mathrm{C}$ nas extremidades por isso os pistões devem ser montados com folgas em relação ao cilindro em razão que quando atingida a temperatura de trabalho o mesmo deslize livremente (TILLMANN, 2013).

O material utilizado na fabricação dos pistões são ligas de alumino e silício. Estes são manufaturados pelo processo de fabricação de fundição e posterior usinagem (KANTOVISCKI, 2011). No início do desenvolvimento dos motores a combustão interna era utilizado o ferro fundido cinzento mas para aplicação em pistões de motores a combustão interna mais isso caiu em desuso (BARROS, 20??). Nos pistões após o seu processo de fabricação para melhorar a sua durabilidade e resistência ao calor são realizados processos de revestimento superficial, zincagem, grafitamento, anodização dura e revestimentos cerâmicos (BARROS, 20??).. 


\section{MATERIAIS E MÉTODOS}

O processo de análise se inicia com a obtenção dos pistões do motor AP1800 , sendo um pistão novo e original e o outro original com algumas horas de uso, e obtendo as informações do fabricante do motor e as informações analíticas, para analisar diversas características do pistão. Após essa primeira etapa foi se desenvolvido os desenhos dos pistões para realizar a análise computacional se utilizando do Ansys Workbench, e assim se obter as tensões que os mesmos estão submetidos.

\section{DADOS DO FABRICANTE}

Os dados obtidos, referentes ao pistão novo e original aqui analisado, do fabricante do motor AP-1800 a gasolina é demostrada no quadro 1.

\begin{tabular}{l|l}
\hline Itens & Dados \\
\hline Código motor & AP-1800 \\
\hline Cilindros & 4 em linha \\
\hline Diâmetro dos cilindros & $81 \mathrm{~mm}$ \\
\hline Curso dos cilindros & $86,4 \mathrm{~mm}$ \\
\hline Tolerância da 1a canaleta & $0,04-0,07 \mathrm{~mm}$ \\
\hline Tolerância da 2a canaleta & $0,02-0,05 \mathrm{~mm}$ \\
\hline Tolerância da 3a canaleta & $0,02-0,05 \mathrm{~mm}$ \\
\hline Combustível & Gasolina \\
\hline Cilindrada & $1781 \mathrm{~cm}{ }^{3}$ \\
\hline Taxa de compressão & $8,5: 1$ \\
\hline Válvulas por cilindro & 2 \\
\hline Potência & $97 \mathrm{cv}$ a $5600 \mathrm{rpm}$ \\
\hline Potência por cilindro & $24,25 \mathrm{cv}$ \\
\hline \multicolumn{1}{c}{ Quadro 1. Dados obtidos do fabricante }
\end{tabular}

Quadro 1. Dados obtidos do fabricante

Outra informação importante obtida é a taxa de compressão do pistão com algum tempo de uso, isso é demostrado na figura 1. 


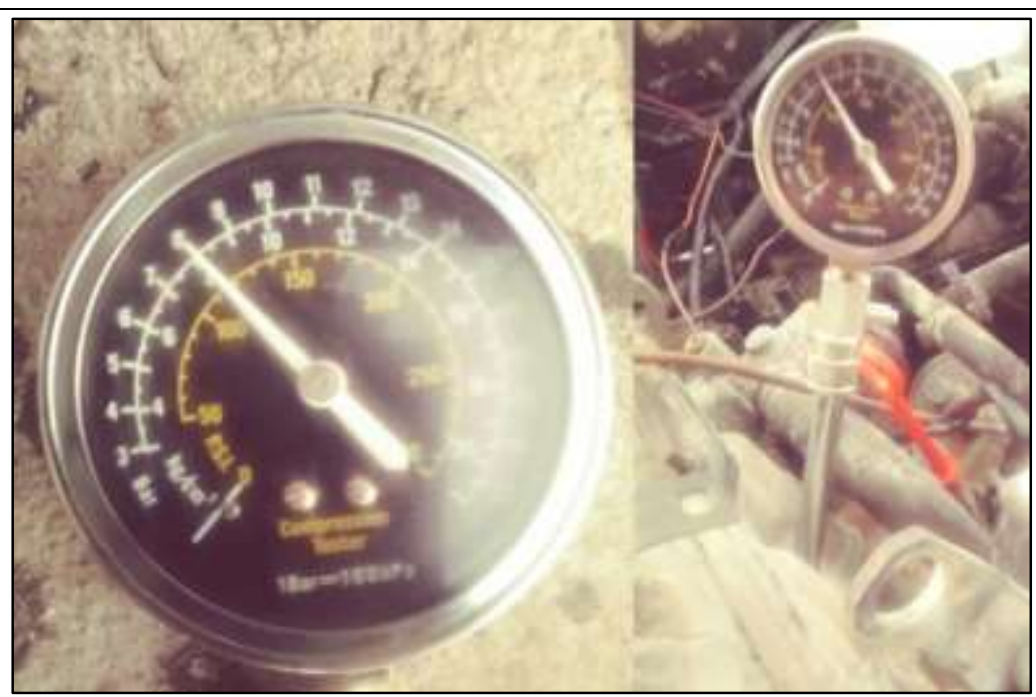

Figura 1. Medição da taxa de

\section{DESENHO DO PISTÃO}

Para realizar a análise foi desenvolvido os desenhos dos pistões a gasolina do motor AP 1.8 no programa SpaceClaim que faz parte do pacote do Workbench do Ansys Student. Na figura 2 demostra a modelagem computacional em 3D dos mesmos.

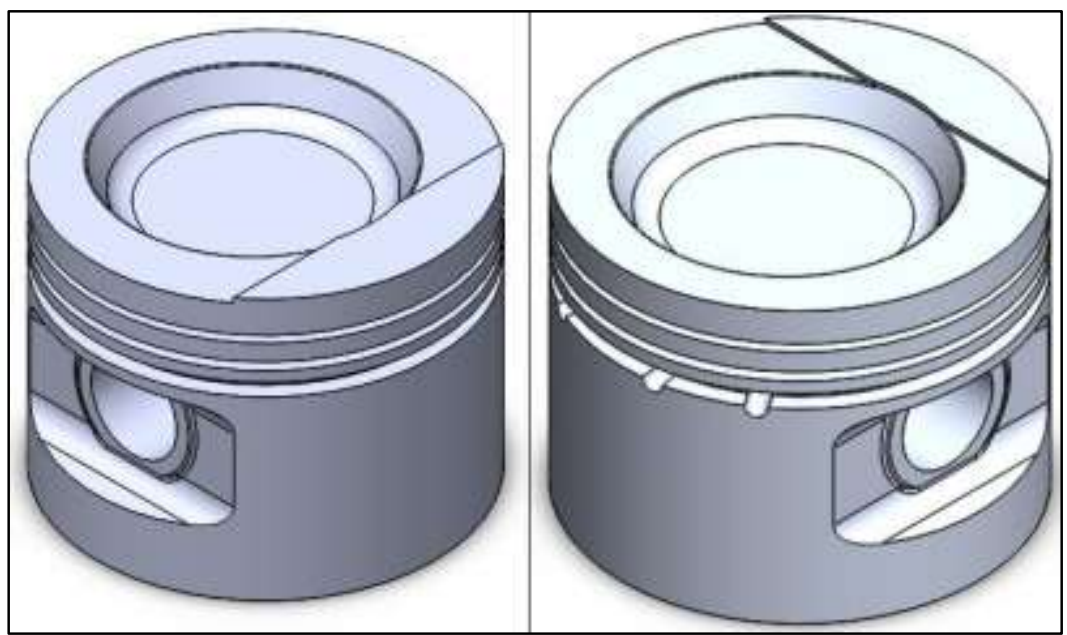

Figura 2 - Pistão Modelagem 3D 


\section{ANÁLISE DO PISTÃO}

Para realizar a análise do pistão é necessário ser divido em quatro etapas, primeiro a avaliação da função do côncavo na face superior do cilindro e o mesmo ser deslocado. Segundo a verificação da razão do furo da biela ser deslocado. Terceiro a análise para o que serve os furos laterais e por último a averiguação dos anéis de vedação e sua função.

\section{CÔNCAVO DA FACE SUPERIOR}

O côncavo na cabeça do pistão é para que se obtenha a taxa de compressão ideal no motor. E com isso se atingindo a taxa de compressão desse motor que é de 8,5:1. O côncavo na cabeça do pistão é deslocado, em torno de $3 \mathrm{~mm}$ do centro do pistão. Isso é realizado devido ao posicionamento das válvulas do motor. E com isso ao entrar o ar no interior do cilindro se obtenha a melhor mistura possível de ar combustível e também ajudar no balanceamento de massa do pistão, pois como o mesmo não é centrado ele retira mais massa de um lado que do outro assim balanceando o pistão. E outro motivo de esta ser deslocada é por causa da centelha da vela, fazendo que o maior volume de ar fique na parte aonde a vela é localizada assim ajudando na melhor queima da mistura ar-combustível.

\section{DESLOCAMENTO DO FURO DA BIELA}

O pistão é construído com o furo da biela deslocado para que no momento em que a pressão gerada pela a expansão dos gases não realize sua força totalmente linear ao centro do virabrequim e sim que realize a força com uma alavanca para que com isso se gera torque no pistão e movimento como consequência. Isso gera um deslocamento no centro de massa do pistão, um desbalanceamento. Assim para balancear o pistão o fabricante do motor adiciona um contrapeso, uma massa adicional para realizar isso. Além disso é realizado o deslocamento do rebaixo da cabeça do pistão realizar o balanceamento. 


\section{FUROS LATERAIS}

Os furos que existe na lateral do pistão, são para a lubrificação do anel, assim lubrificando a camisa no local que o pistão realiza o seu deslocamento. O fluxo de óleo é direcionado para a parte inferior do pistão através dos furos para realizar a lubrificação do pistão. Esse é óleo é injetado para o interior do pistão pelos os injetores.

\section{ANÉIS DE VEDAÇÃO}

A função principal dos anéis é impedir o contato entre os pistões e os cilindros, como o pistão trabalha no interior do cilindro tivesse contato entre eles e não fosse se utilizado os anéis teria um atrito muito elevado e com isso reduzindo a eficiência do motor e sua durabilidade. E com a utilização anéis de vedação tem uma folga entre os pistões e o cilindro, pois como os anéis são expansíveis eles compensam essa diferença, e ainda eles compensam a diferença da expansão térmica dos materiais. E também sem eles não se conseguiria gerar a pressão de compressão no cilindro. Outra função dos anéis é impedir a passagem do óleo do cárter para a câmara de combustão, assim ele remove o excesso desse óleo e deixa apenas uma pequena película afim somente de diminuir o atrito do motor.

\section{ANÁLISE COMPUTACIONAL DO PISTÃO}

Para realizar a análise computacional dos pistões foi se utilizado o software Ansys workbench. Aonde os pistões foram primeiramente submetidos a uma pressão de 60 bar e a uma temperatura no centro de 430 ․ C. A figura 3 demostra as análises computacionais de ambos para a distribuição da temperatura. 


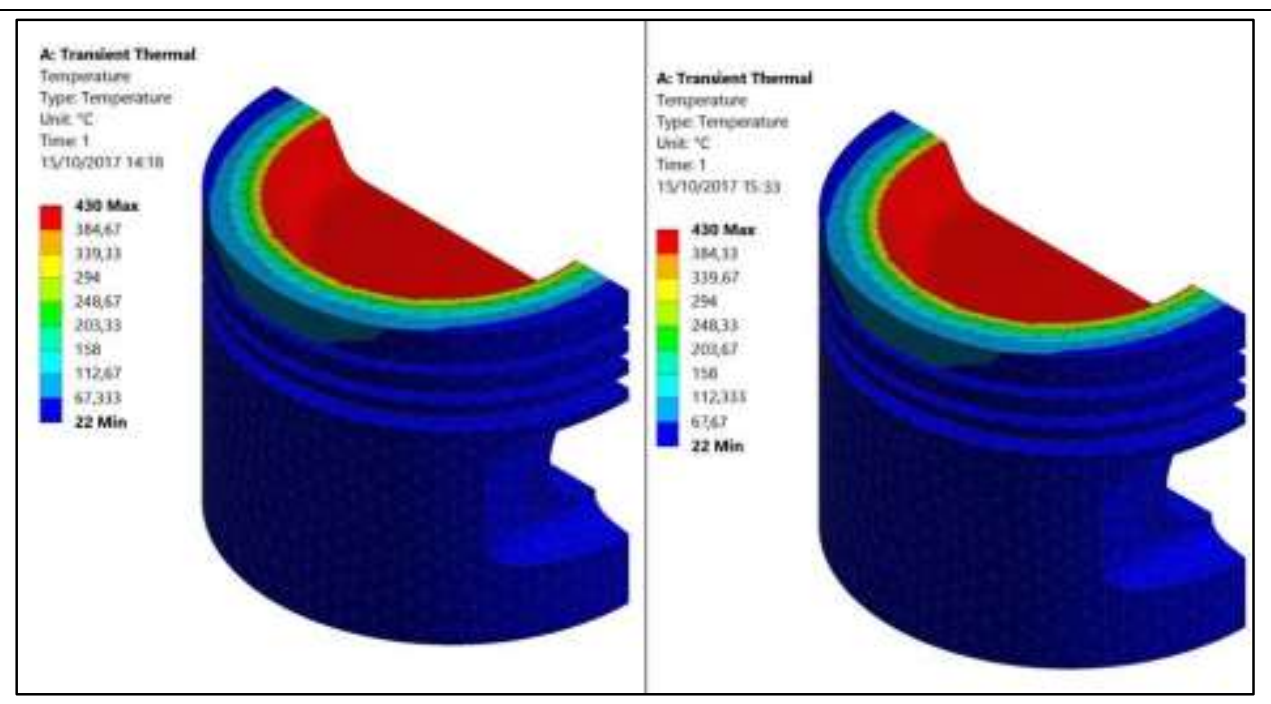

Figura 3 - Distribuição da temperatura nos pistões

Assim se observa com essa simulação que a distribuição do calor sobre os ambos os pistões é idêntica, tanto para o novo quanto para o usado. Após a simulação da distribuição da temperatura é realizada a simulação das tensões sobre os pistões que é demostrada na figura 4. 


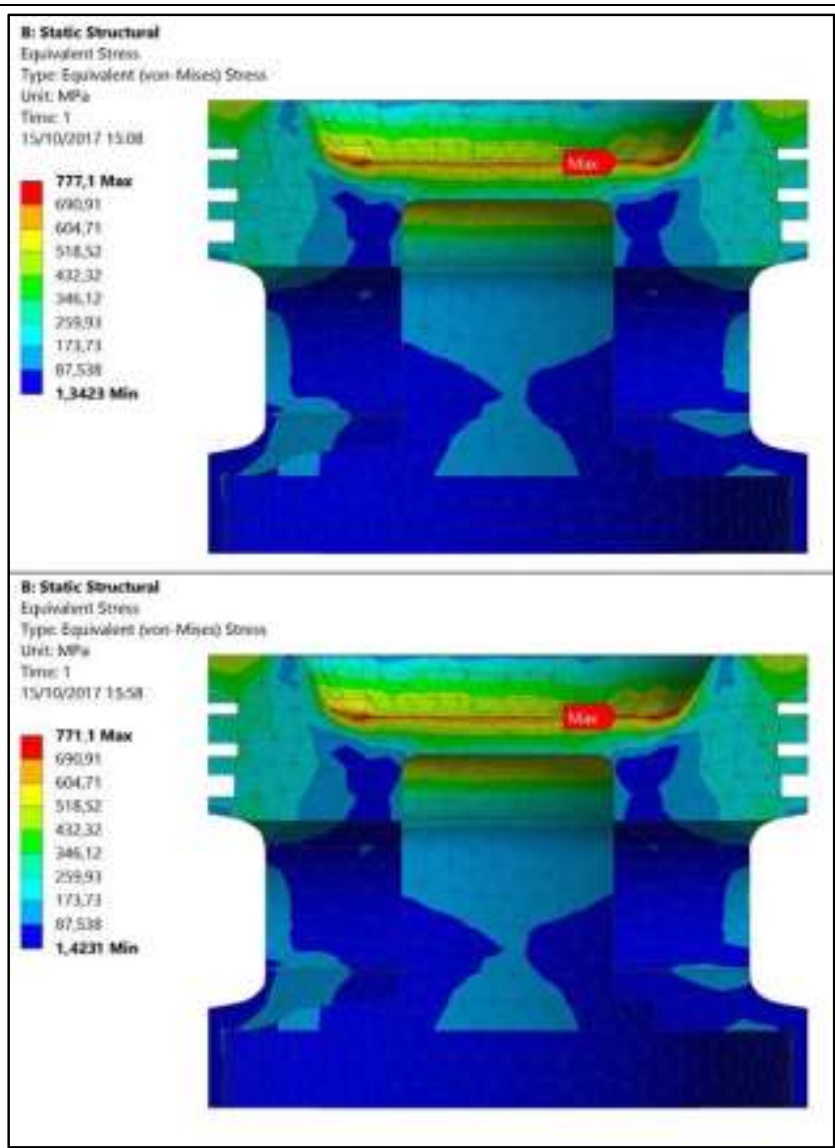

Figura 4. Simulação computacional das tensões nos pistões

\section{RESULTADOS E DISCUSSÃO}

Com as informações obtidas sobre os dois pistões podemos montar a quadro 2 analisando os resultados obtidos nessa análise. 


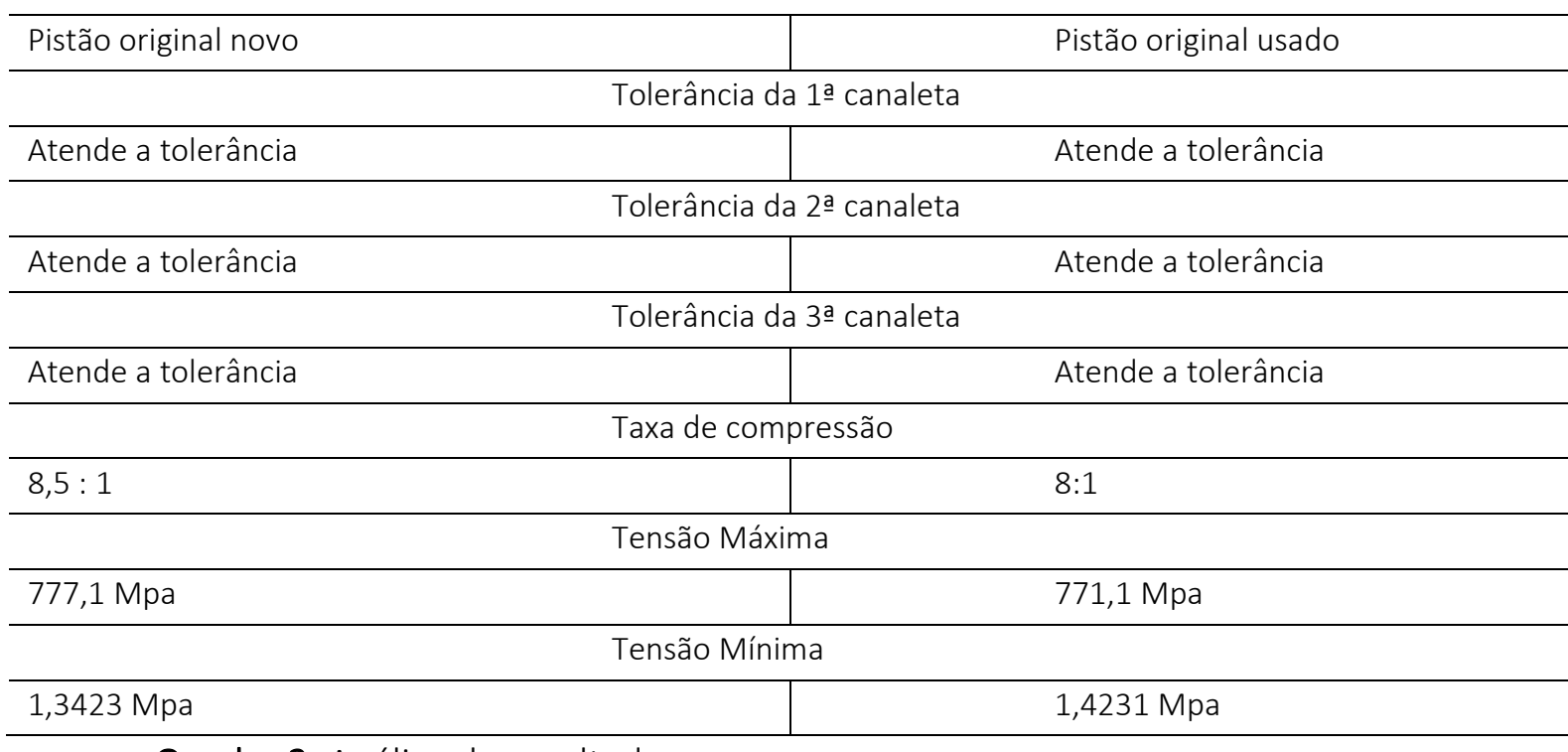

Quadro 2. Análise de resultados

Com isso pode se ver que houve uma pequena diferença entre as taxas de compressão do motor com o pistão novo e original com o motor com o pistão usado e original. Os dois atenderam as tolerâncias especificas pelo fabricante. E entre eles houve apenas uma pequena diferença nas tensões máxima e mínimas isso se devido as diferenças do processo de fabricação.

As características de torque, potência para ambos foi considerada a mesma, pois devido à falta de acesso a equipamentos como um dinamômetro de banca para teste de motores isso não foi analisado no motor em que o pistão usado trabalha.

\section{CONCLUSÕES}

Este trabalho teve como objetivo geral realizar a análise de um pistão, analisando diversas informações obtidas sobre o pistão como potência especifica desse motor, a taxa de compressão que ele é submetido e realizando uma análise computacional da geometria construtiva de mesmo.

No primeiro capítulo foi levantado alguns conceitos para este trabalho foi elaborado o referencial bibliográfico, e no segundo capítulo aonde foi realizada toda a pesquisa necessária para o desenvolvimento. 
Deste modo, foi possível obter os resultados alcançados neste trabalho, sendo que o pistão a gasolina terá uma boa durabilidade, torque, potência e trabalha com taxas de compressão não muito elevadas. Assim sendo, os motores a gasolina apresentam ainda vantagens quando trabalham em temperaturas mais baixas.

Desta maneira, foi possível resolver o problema do trabalho e alcançar os objetivos propostos. Tendo como sugestão para trabalhos futuros a realização de uma análise de um cabeçote, das bielas e do virabrequim, para obter resultados detalhados dos componentes de um motor.

\section{REFERÊNCIAS}

KNIES, G. G. (2010). Análise Estatística da diferença do volume minimo de um cilindro de um motor a combustão interna entre o modelo $3 \mathrm{~d}$ e o produzido. Porto Alegre.

TILLMANN, C. A. (2013). Motores de Combustão Interna e seus Sistemas. Pelotas.

Rossignac, J. R., \& Requicha, A. A. (20??). Solid Modeling. Los Angeles.

ESALQ, Aula 5 - Motores de combustão interna - Parte I . (20??). Fonte: Esalq: http://www.esalq.usp.br/depart amentos/leb/aulas/leb332/AULAS\%202017/Aula\%205\%20\%20Motores\%20de\%20combustao\%20interna\%20I/Motores\%20 de\%20combustao\%20interna\%20l_2017_TEXTO.pdf

BRUNETTI, F. (2013). Motores de combustão interna. São Paulo: Edgard Blücher Ltda.

VARELLA, C. A. (20??). Pricipios de Funcionamento dos Motores de Combustão Interna. Seropédica.

SILVEIRA, F. L. (27 de Maio de 2013). http://www.if.ufrgs.br. Fonte: Instituto de Física: http://www.if.ufrgs.br/cr ef/?area=questions\&id=87

FERRAZ, F. (2008). https://fabioferrazdr.files.wordpress.com. Fonte: fabioferraz: https://fabioferrazdr.files.wor dpress.com/2008/08/mci1.pdf

KANTOVISCKI, A. R. (2011). Engenharia de Materiais nos Projetos Automotivos.

BARROS, J. E. (20??). Componentes de Motores de Combustão Interna. 